\title{
SpS10: Dynamics of the star-planet relations
}

No contribution was received from this Joint Discussion. 